\title{
Piezosensors for Monitoring Degradation of Automotive Engine Oil
}

\author{
ALI JASIM MOHAMMED, MARWA ABDUL MUHSIEN HASSAN \\ Department of Physics, College of Science, Al-Mustansiriyah University, Baghdad, Iraq. \\ E-mail: spiritjabir@yahoo.com \\ E-mail:marwa_alganaby@yahoo.com
}

\begin{abstract}
Effect of heating times on piezoelectric sensing of engine oil has been investigated with different heating times $(0,15,30,45$ and 60$)$ min. Sensing signals (piezoelectric) characterized and achieved by using transducer which transmits a mechanical waves towards the glucose solution cell, and then the receptor received the attenuated signals. The range of operating frequencies was $(950 \mathrm{kHz}-50 \mathrm{MHz})$, the results of measurement which included recording the resonance frequencies (in the first order) for all prepared samples. The results showed that the resonance frequency shifted to the higher values (from $12 \mathrm{MHz}$ to $26 \mathrm{MHz}$ ) for heating times (from 0 to $60 \mathrm{~min}$ ) of engine oil.
\end{abstract}

Key words: engine oil, piezoelectrical properties, resonance frequency, Damping Coefficient.

\section{BACKGROUND}

Internal combustion engines in automobiles and other vehicles can only perform efficiently if there is proper lubrication between moving parts. Automotive engine oil is a mixture of base stock, and a number of additives which improve the operational properties of the lubricating oil [1]. Engine oils are susceptible to degradation by oxygen, increased temperature, and shear stress. The degradation of oil is very complex process and affects mainly additives and afterwards, oxidation of the base stock leads to formation of different acidic products, especially carbonic acids, and polymerization processes. The reduced lubrication capabilities caused by inadequate oil viscosity will damage the engine [2] Thus, there is a need to design a sensor device which can tell us about chemical oil quality, by monitoring these directly in the oil. A variety of sensor devices have been proposed to monitor the degradation based on different parameters such as viscosity [3], conductivity [4], and acidity [5]. Further improvements were carried out by introducing molecular recognition properties in sensitive layers to determine the chemical quality of engine oil in gas or liquid phase by employing mass sensitive transducers [6-8]. Recently, dielectric spectroscopy has also been employed to detect the age of used engine oil [9]. In this paper, we have analyzed the piezoelectric properties of Engine oil.

\section{EXPERMINTAL WORK}

The material used in this paper is (super diesel engine oil meets API service $C F$, produced and packaged by petromin corporation, Saudi Arabia) at $90{ }^{\circ} \mathrm{C}$ heating temperature with different heating times.
The effect of heating times $(0,15,30,45$ and 60$)$ min on piezoelectric sensing of engine oil was measured. The setting used in this paper include a standard two piezo-crystals (Model number: 3B12+9.0EAWC, Type: Piezoelectric Ceramics, Material: Piezoceramics, Metal type: Brass, Electrode form: (Thin) Diode, Connection terminal: Soldier wire or not, Parameter value: $(D=12 \mathrm{~mm}, T=0.15 \mathrm{~mm}$ and $\mathrm{f}=9 \mathrm{kHz})$ ) located tightly on the copper foil as a diaphragm shown in Fig. (1).



Fig. 1: Image of piezo-crystal used in this work.

\section{RESULTS}

The resonance frequency can be determined by measuring the output voltage as a function of frequency as shown in Fig. (2), we can observed that the resonance value varied as the frequency sweept from $950 \mathrm{kHz}$ to $50 \mathrm{MHz}$ at different heating times and fixed teamperature at $90{ }^{\circ} \mathrm{C}$, this varied can be due to a number of reasons, such as humidity, atmospheric pressure and mechanical loading. The effect of heating times on resonance frequency can be seen in Fig. (3). 


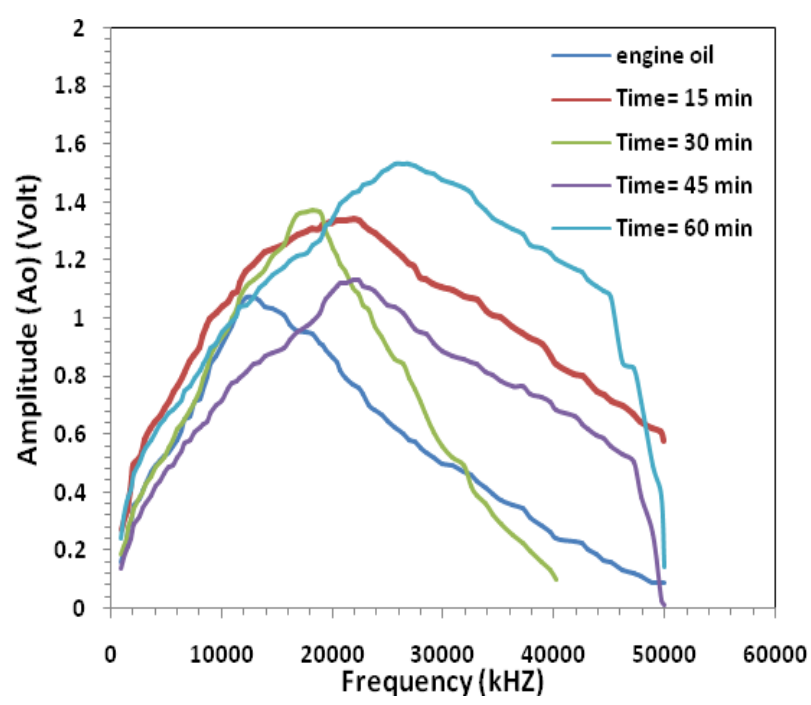

Fig. 2: The resonance frequency of engine oil at different heating times and $90^{\circ} \mathrm{C}$ heating temperature.

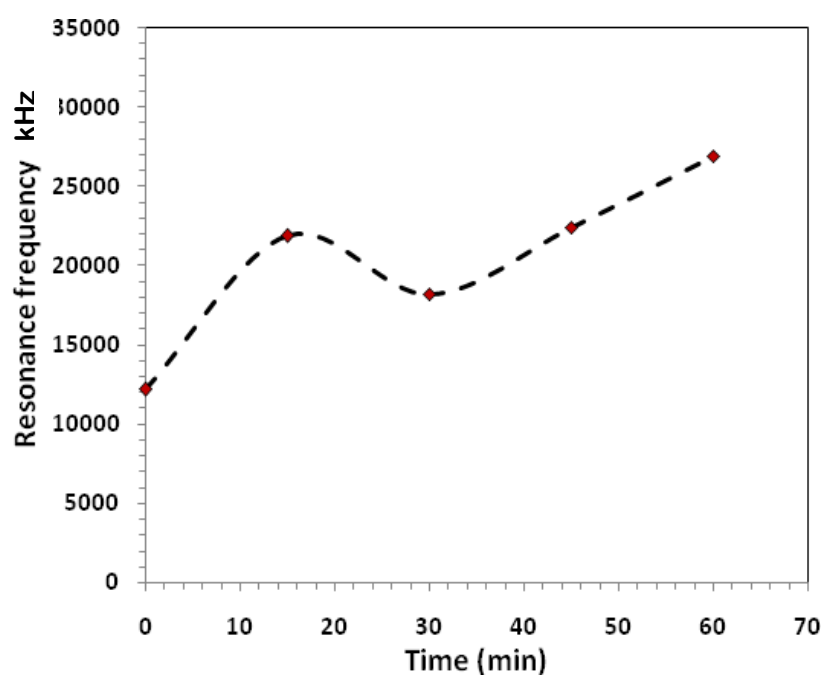

Fig. 3: Effect of heating times on resonance frequency of engine oil.

The damping coefficient $\left(\delta_{\mathrm{D}}\right)$ can be calculated using the relation [10]:

$$
h(t)=A_{o} \exp (-t / \tau) \sin (\omega t)
$$

where:

$\left(A_{\circ}\right)$ is the amplitude at resonance,

$(t=1 / f),(f)$ is the frequency,

$(\omega=2 \pi f)$,

$(\mathrm{T})$ is the resonance time.

Fig. (4) (a, b, c, d and e) shown the damping behavior of the wave for different heating temperature. The damping coefficient $\left(\delta_{D}\right)$ of the water solution at different heating times were carried out from the graph and using the relation [10]:

$\delta_{\mathrm{D}}=A_{1} / A_{2}$
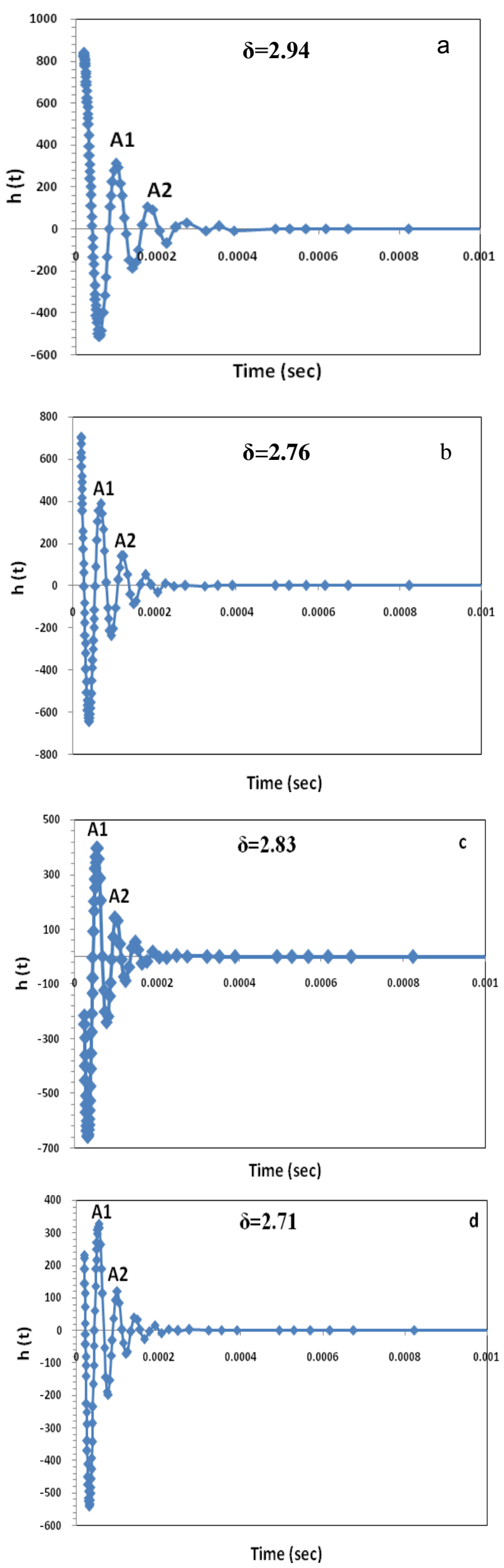




Fig. 4: Relation between the time of resonance and damping coefficient for engine oli at $90^{\circ} \mathrm{C}$ with different heating times: a- engine oil, $b-15 \mathrm{~min}, c-30$ min, d-45 min and e- 60 min.

The shift of resonance frequency between the incident ( reference ) signal and that tramsmitted from engine oil at different heating temperature addition are shown in Fig. (5) (a, b, c, d and e), it is clearly that the large shifting vanish with increasing the source frequency.


Fig.5: The incidint frequencies (upper) and the sensing frequencies (lower) by the engine oil at different heating times: a- engine oil, b-15 min, c-30 min, d-45 min and e- 60 min.
The characteristic ( priciple) frequency can be calculated depending on the band width and the quality factor as in relation [11]:

$$
\mathrm{B}=\mathrm{f}_{\mathrm{e}} / Q
$$

Where:

$f_{e}$ : the characteristic frequency.

Q: the quality factor.

The acoustic is traveling through the engine oil with velocity depending on the material addition of the water solution and on the characteristic frequency, and then the velocity could be evaluated using the relation below [11]:

$t=\lambda / 2=V_{s} / 2 f_{e}$

where

$t=$ The plate thickness,

$V_{s}=$ The velocity of sound.

The quality factor was esteemed by using the relation [12]:

\section{$\mathrm{Q}=\pi / \ln \delta$}

As we observed the value of the quality decrease when the resonance frequency increase, our results were tabulated in the table (1).

Table (1): The result of piezoelectric properties.

\begin{tabular}{|c|c|c|c|c|c|c|}
\hline $\begin{array}{c}\text { Heating } \\
\text { times } \\
(\mathrm{min})\end{array}$ & $\mathrm{f}_{\mathrm{o}}(\mathrm{kHz})$ & $\begin{array}{c}\text { Band } \\
\text { width } \\
(\mathrm{kHz})(\mathrm{B})\end{array}$ & $\begin{array}{c}\text { Dam- } \\
\text { ping } \\
\text { coeff. } \\
(\delta)\end{array}$ & $\begin{array}{c}\text { Quality } \\
\text { factor } \\
(\mathrm{Q})\end{array}$ & $\begin{array}{c}\text { Surface } \\
\text { Acoustic } \\
\text { wave } \\
\text { velocity } \\
\left(\mathrm{V}_{\mathrm{s}}\right)\end{array}$ & $\begin{array}{c}\text { Characteristic } \\
\text { frequency } \\
(\mathrm{fe}) \\
(\mathrm{kHZ})\end{array}$ \\
\hline $\begin{array}{c}\text { Engine } \\
\text { oil }\end{array}$ & 12185.5 & 758.14 & 2.94 & 2.90 & 3398.23 & 2205.84 \\
\hline 15 & 18187.3 & 951.01 & 2.76 & 3.08 & 4516.12 & 2931.48 \\
\hline 30 & 21885.7 & 972.43 & 2.83 & 3.00 & 4507.58 & 2925.93 \\
\hline 45 & 22415.7 & 800.43 & 2.71 & 3.13 & 3871.37 & 2512.96 \\
\hline 60 & 26909.9 & 1084.89 & 2.73 & 3.11 & 5213.83 & 3384.37 \\
\hline
\end{tabular}

\section{CONCLUSION}

In this paper, effect of heating times on piezoelectric sensing of engine oil has been investigated with different heating times $(0,15,30,45$ and 60$) \mathrm{min}$. The results showed that the resonance frequency shifted to the higher values (from to $12 \mathrm{MHz}$ to $26 \mathrm{MHz}$ ) for heating times (from 0 to $60 \mathrm{~min}$ ) of engine oil.

\section{REFERENCES}

[1] Dickert, F.L.; Forth, P.; Lieberzeit, P.A.; Voigt, G. Quality control of automotive engine oils with mass-sensitive 
chemical sensors-QCMs and molecularly imprinted polymers. Fresenius' J. Anal.Chem. 2000, 366, 802-806.

[2] Lieberzeit, P.A.; Glanznig, G.; Leidl, A.; Voigt, N.; Dickert, F.L. Nanostructured polymers for detecting chemical changes during engine oil degradation. Sens. J. IEEE 2006, 6, 529-535.

[3] Agoston, A.; Ötsch, C.; Jakoby, B. Viscosity sensors for engine oil condition monitoringApplication and interpretation of results. Sens. Actuat. A Phys. 2005, 121, 327-332.

[4]Moon, S.-I.; Paek, K.-K.; Lee, Y.-H.; Kim, J.-K.; Kim, S.-W.; Ju, B.-K. Multiwall carbon nanotube sensor for monitoring engine oil degradation. Electrochem. Solid State Lett. 2006, 9, $\mathrm{H} 78-\mathrm{H} 80$.

[5] Wang, S.S. Engine oil condition sensor: Method for establishing correlation with total acid number. Sens. Actuat. B Chem. 2002, 86, 122-126.

[6] Sepcic, K.; Josowicz, M.; Janata, J.; Selby, T. Diagnosis of used engine oil based on gas phase analysis. Analyst 2004, 129, 1070-1075.

[7] Latif, U.; Rohrer, A.; Lieberzeit, P.; Dickert, F. QCM gas phase detection with ceramic materials-VOCs and oil vapors. Anal. Bioanal. Chem. 2011, 400, 2457-2462.

[8] Mujahid, A.; Afzal, A.; Glanzing, G.; Leidl, A.; Lieberzeit, P.A.; Dickert, F.L. Imprinted sol-gel materials for monitoring degradation products in automotive oils by shear transverse wave. Anal. Chim. Acta 2010, 675, 53-57.

[9] Guan, L.; Feng, X.L.; Xiong, G.; Xie, J.A Application of dielectric spectroscopy for enginelubricating oil degradation monitoring. Sens. Actuat. A Phys. 2011, 168, 22-29.

[10] S. I. Baskalov, "Signals and Circits , Problems Solving Guide “, Mir Publishing, Moscow, 1990.

[11] J.Lu, " Quality Factor of PZT thin film transducer micro cantilevers", Stresa, Italy, 26-28 April 2006.

[12] S. Humad, R. Abdolvand , G. Ho , G. Piazza, and F. Ayazi , Proc. IEEE Int. Electron. Devices Meeting, 957-960, 2003. 